\title{
Global comparison of phosphoproteins in human and rodent hearts: implications for translational studies of myosin light chain and troponin phosphorylations
}

\author{
K. Kotlo' ${ }^{1}$ A. M. Samarel ${ }^{2}$, H. Y. Chen ${ }^{3}$, J. Aldstadt ${ }^{4}$ and R. S. Danziger ${ }^{1,5^{*}}$
}

\begin{abstract}
Cardiac remodeling and failure are regulated by a myriad of cardiac protein phosphorylations. In the present study, cardiac phosphoprotein patterns were examined in rodent and human hearts Left ventricular tissue samples were obtained from human systolic failing $(n=5)$ and control $(n=5)$ hearts and from two rat models of hypertensive heart failure, i.e., spontaneously hypertensive heart failure and Dahl salt-sensitive rats and corresponding controls. Phosphoproteins were separated by 2D-DIGE with Cydye staining, phosphoprotein patterns were analyzed using pixel intensity in rectified images. Specific phosphoproteins which were different in human versus rodent hearts were identified by MALDI-TOF/TOF Mass Spectrometry. Targeted pair-wise analyses showed differences $(p<0.05)$ in $26 \%$ of the pixels, which included pixels containing phosphorylated troponin T, myosin light chain, peroxiredoxin, and haptoglobin. These results show differences in rodent versus human cardiac remodeling which will influence the translation rodent studies to humans in this area.
\end{abstract}

\section{Background}

Rodents have become a mainstay for many studies of molecular mechanisms and signaling in cardiac failure. Hypertensive rats undergo a similar morphologic progression in cardiac remodeling, including a phase of concentric hypertrophy followed by dilation and systolic failure, as observed in human hypertension.

Current evidence is overwhelming that protein phosphorylations play a key role in regulating cardiac function/remodeling and contractility in heart failure. First, a number of serine-threonine protein kinases and kinase signaling pathways have been shown to be capable of regulating features of cardiac remodeling. Among these are Phosphoinositide 3-Kinase (Cantley 2002; Shioi et al. 2000), Akt (Shiojima and Walsh 2006; Schiekofer et al. 2006; Wohlschlaeger et al. 2007). GSK-3 (Shioi et al.

\footnotetext{
*Correspondence: rdanzig@uic.edu

5 Jesse Brown Veterans Administration, 820 S. Damen,

Chicago, IL 60612, USA

Full list of author information is available at the end of the article
}

2000; Matsui et al. 2002; Blankesteijn et al. 2008), transforming growth factor- (Wrana et al. 1994; Liu et al. 2006), $\mathrm{Ca}(2+)$-calmodulin-dependent protein kinase (Zhu et al. 2003; Zhang et al. 2002, 2005), cAMP-dependent protein kinase (Benkusky et al. 2007; Lai et al. 2008) (Takahashi et al. 2006; Fukuda et al. 2005), Protein kinase D1 (Fielitz et al. 2005; Harrison et al. 2006), Mitogenactivated protein kinases (Frantz et al. 2007), and Protein kinase C (Agnetti et al. 2007; Sumandea et al. 2004; Sumandea et al. 2003). Second, protein phosphatases, e.g., phosphatases 1 (PP1 and PP2) (Grote-Wessels et al. 2008) (Gupta et al. 2003, 2005) (Grote-Wessels et al. 2008; Pathak et al. 2005) and Calcineurin (Dousa 1999). (Van Oort et al. 2006) (Sakata et al. 2000; Heineke et al. 2005), regulate cardiac remodeling in heart failure. Third, a number of phosphoproteins identified that may be proximal mediators of cardiac remodeling are increasing: These include Phospholamban (PLN), (Napolitano et al. 1992; Movsesian et al. 1990; Vittone et al. 2008; Altschuld et al. 1995; Schwinger et al. 1998; Desantiago et al. 2008); Connexin 43 (Akar et al. 2004; Ai and Pogwizd 2005), 
Endothelial nitric oxide synthase (eNOS) (Gill et al. 2005), histone deacetylase (HDAC) (Zhang et al. 2002), Protein kinase C (Vega et al. 2004), a variety of myofilament proteins (Belin et al. 2007), including troponin I (Milting et al. 2006); myosin light chain (Papp et al. 2003), and the cAMP response element binding protein (Takeishi et al. 2002; Muller et al. 1995, 1998, 2001; Matus et al. 2007); the Ryanidine Receptor (RyR) (Lehnart et al. 2005) and O transcription factor (Skurk et al. 2005; Vahtola et al. 2008). Delineation of cellular phosphoprotein signaling pathways is the result of numerous distinct studies using a wide variety experimental models, including in vitro studies with cell culture, isolated proteins, isolated cardiac myocytes, in vitro work with cardiac preparations and whole animals from numerous species and strains over the past 70 years.

In the present study, we have examined and compared phosphoprotein patterns in humans versus rodent hearts. The important question we asked in the present study is translational feasibility and efficacy of findings of rodent heart failure studies to human subjects.

The aims of the study were to compare phosphoprotein patterns (1) in human and rodent hearts and (2) between and within hearts.

\section{Methods}

\section{Human hearts}

Left ventricular tissue from non-failing and failing human hearts. Samples of left ventricular (LV) tissue were obtained from Loyola University Health System's (LUHS's) Cardiovascular Institute Tissue Repository, and from the Gift of Hope Organ and Tissue Donor Network. The investigation conformed to the principles outlined in the Declaration of Helsinki. A detailed protocol and informed consent document were reviewed by LUHS's Institutional Review Board prior to tissue procurement. Following informed consent, explanted LV tissue was obtained from patients undergoing heart transplantation for nonischemic, dilated cardiomyopathy (DCM). Tissue samples were quick-frozen in liquid $\mathrm{N}_{2}$ in the operating room and stored at $-80{ }^{\circ} \mathrm{C}$. Following informed consent from organ donor family members, nonfailing (NF) donor hearts judged unsuitable for cardiac transplantation were stored in cardioplegic solution on ice and were delivered within $4 \mathrm{~h}$ of cardiac extirpation by the Gift of Hope Organ and tissue Donor Network. Tissue samples were then quickly frozen in liquid $\mathrm{N}_{2}$, and stored at $-80^{\circ} \mathrm{C}$.

\section{Rodent hearts}

2D-DIGE images of phosphoprotein were extracted from paired strains of failing and control rats strains, i.e., (1) Dahl salt-sensitive (S) (failing) versus resistant (R) (control) rat; and (2) Spontaneously hypertensive stroke prone (SHHF) (failing) and Wistar (control) rat strains and as previously reported and described (Kotlo et al. 2012).

\section{Protein preparation with phospho-enrichment}

Total protein extracts were obtained by dounce homogenizing (left ventricular tissue) and resuspending pelleted regenerated cardiomyocytes in RIPA buffer containing a protease inhibitor cocktail mixture (Calbiochem) with phosphatase inhibitors $(50 \mathrm{mM}$ sodium fluoride, $1 \mathrm{mM}$ sodium orthovanadate and $1 \mathrm{mM}$ sodium pyrophosphate). The homogenate was centrifuged at $14,000 \mathrm{rpm}$ for $15 \mathrm{~min}$ at $4{ }^{\circ} \mathrm{C}$, and the supernatant subjected to phosphoenrichment of proteins using a Phosphoprotein purification kit supplied by Qiagen Inc according to the manufacturer's instructions.

2-D DIGE with Cydye staining was performed for ingel comparison of cardiac phosphoproteins. Phosphoenriched proteins were dissolved in 2-D lysis buffer (7 M urea, $2 \mathrm{M}$ thiourea, $4 \%$ CHAPS, $30 \mathrm{mM}$ Tris- $\mathrm{HCl}, \mathrm{pH}$ 8.8). Protein concentration was determined using the BioRad protein assay method and samples diluted with 2-D lysis buffer to protein concentration between 5 and $8 \mathrm{mg} /$ ml. 1.0 $\mu \mathrm{L}$ of diluted CyDye (1:5 diluted with DMF from $1 \mathrm{nmol} / \mu \mathrm{L}$ stock) is added to $30 \mu \mathrm{g}$ of protein extract. Cy2 was used for control samples and Cy5 was used for heart failure samples. The mixture was vortexed and then incubated under dark conditions on ice for $30 \mathrm{~min}$. $1.0 \mu \mathrm{L}$ of $10 \mathrm{mM}$ Lysine was added to each of the samples to quench the reaction, followed by vortexing and incubation under dark conditions on ice for an additional $15 \mathrm{~min}$. Cy 2 and $\mathrm{Cy} 5$ labeled samples were mixed together and the appropriate volume of 2X 2-D Sample Buffer (8 M urea, $4 \%$ CHAPS, $20 \mathrm{mg} / \mathrm{ml} \mathrm{DTT,} 2 \%$ pharmalytes, and trace amounts of bromophenol blue) and $100 \mu \mathrm{L}$ of destreak solution (GE Healthcare) was added to the samples. Rehydration buffer ( $7 \mathrm{M}$ urea, $2 \mathrm{M}$ thiourea, $4 \%$ CHAPS, $20 \mathrm{mg} / \mathrm{ml} \mathrm{DTT,} 1 \%$ pharmalytes, and trace amounts of bromophenol blue) was added to reach a total volume of $250 \mu \mathrm{L}$. The samples were mixed, spun, and equal amounts of protein were loaded onto $13 \mathrm{~cm}$ IPG strips (pH 3-10 linear) under $1 \mathrm{ml}$ mineral oil. Isoelectric focusing was performed for $12 \mathrm{~h}$ at $20^{\circ} \mathrm{C}$ with 50 $\mu \mathrm{A} /$ strip. The focused IPG strips are loaded into the $12 \%$ SDS-gels and ran at $15{ }^{\circ} \mathrm{C}$ until the dye front ran out of the gels. Image scans are carried out immediately following the SDS-PAGE using Typhoon TRIO (Amersham BioSciences) according to the manufacturer's instructions.

\section{Image registration}

Scanned 2D-DIGE images were analyzed by Image QuantTL software (GE-Healthcare). The scanned gel 
images were saved as grayscale Tagged Image File Format (TIFF) files. Each pixel in these files had an intensity value that ranged from integers 0 to 255 . Rectification points were determined by visual examination of each of the gels. Each image file was annotated with the location of 19 common points that were used for image registration (Fig. 1). All the images were transformed using spline interpolation functions available in ESRI ArcMap 10.1 software. This transformation ensures that the locations of the 19 control points are preserved exactly and the locations of pixels between the control points are transformed using a smooth function (Brown 1992). The resulting images were resampled and cropped to a box that bounds the control points. The resulting images contained 509 rows and 489 columns for a total of 248,901 pixels.

\section{MALDI-TOF/TOF mass spectrometry}

Protein spots were excised by Ettan Spot Picker (GE Healthcare) and washed multiple times to remove staining Cy dyes and other inhibitory chemicals. Gel spots were dried and then rehydrated in digestion buffer containing sequencing grade modified trypsin. Proteins were digested in-gel at $37{ }^{\circ} \mathrm{C}$ and digested peptides are extracted from the gel with TFA extraction buffer and shaking. The digested tryptic peptides were desalted using C-18 Zip-tips (Millipore) and then mixed with CHCA matrix (alpha-cyano-4-hydroxycinnamic acid) and spotted into the wells of a MALDI plate. Mass spectra (MS) of the peptides in each sample were obtained using an ABSciex 4700 Proteomics Analyzer and ten to twenty of the most abundant peptides in each sample were further subjected to fragmentation and tandem mass spectrometry (MS/MS) analysis. The combined MS and MS/MS spectra were submitted for database search using GPS Explorer software equipped with the MASCOT search engine to identify proteins from the NCBI non-redundant protein database. Proteins identified with a confidence interval (C.I.) greater than $99 \%$ are reported.

\section{Statistics}

The differences between sets of images were examined on a pixel by pixel basis. Spot abundance was determined by average pixel value of "ovals" containing spots identified

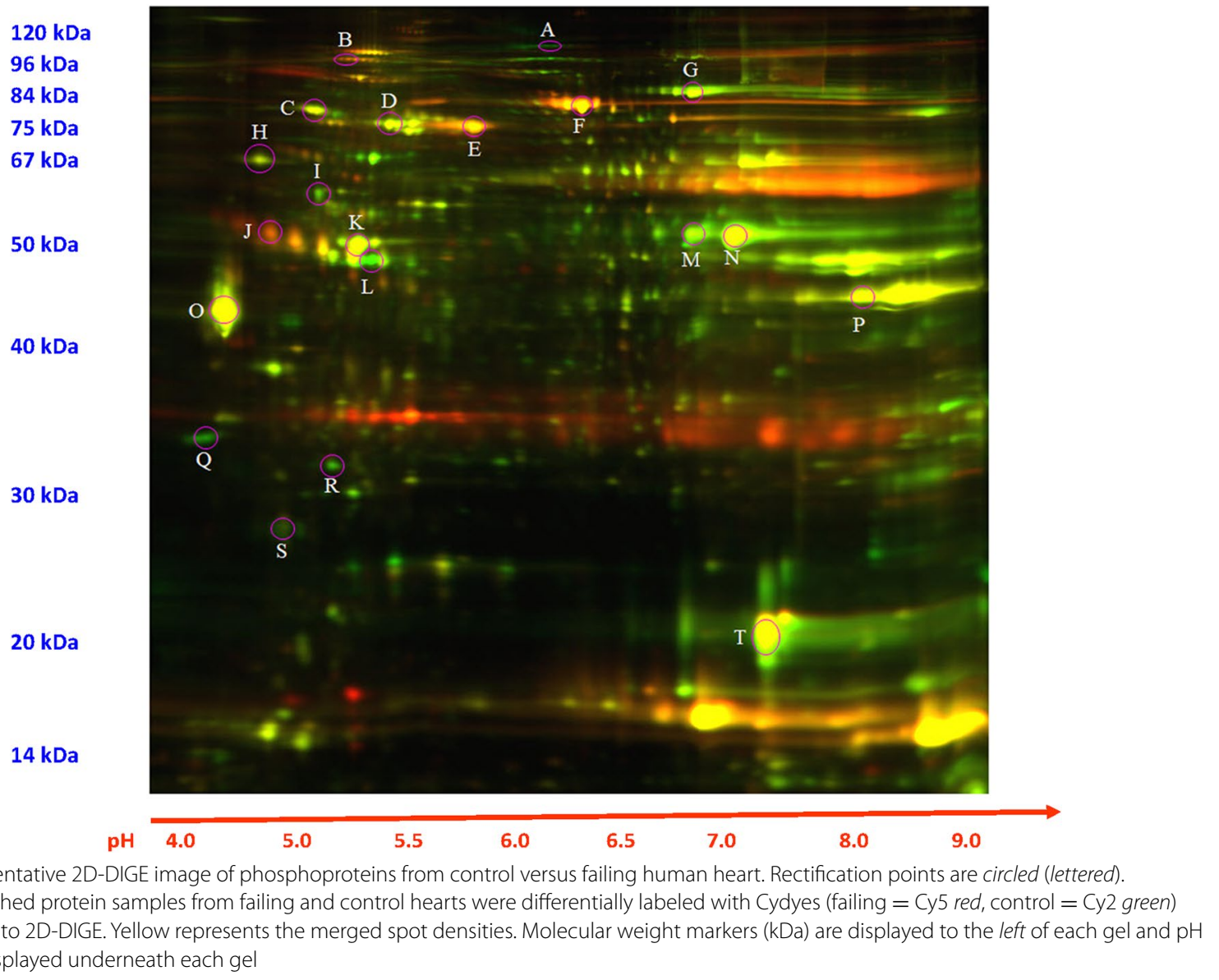


Table 1 Human heart samples analyzed by 2D-DIGE and MALDI-TOF

\begin{tabular}{|c|c|c|c|c|c|}
\hline Sample ID & Age & Gender & Race & Ejection fraction & Cause of death \\
\hline DCM24 & 55 & $M$ & Black & $5 \%$ & DCM \\
\hline DCM25 & 45 & $M$ & White & $5 \%$ & DCM \\
\hline DCM33 & 23 & $M$ & Black & $15 \%$ & DCM \\
\hline DMC40 & 33 & $M$ & White & $15 \%$ & DCM \\
\hline DMC41 & 22 & $F$ & Black & $10 \%$ & DCM \\
\hline NF3 & 44 & M & White & Echo: none done Cardiac Cath: not done & $\begin{array}{l}\text { Paranoid Schizophrenia; acute subdural } \\
\text { hematoma }\end{array}$ \\
\hline NF9 & 50 & $\mathrm{~F}$ & Hispanic & $\begin{array}{l}\text { Echo: Normal LVEF/hyperdynamic/possible mild LVH/No } \\
\text { obvious vascular lesions, no RWMA, mild pericardial effusion } \\
\text { Cardiac Cath: normal coronary arteries, no disease or steno- } \\
\text { sis, normal size, normal LV systolic function, EF }>70 \%\end{array}$ & $\begin{array}{l}\text { Left basal ganglia hemorrhagic stroke; } \\
\text { chronic paroxysomal Afib, HTN, } \\
\text { depression, renal insufficiency, NIDDM }\end{array}$ \\
\hline NF16 & 40 & $\mathrm{~F}$ & Black & $\begin{array}{l}\text { Echo: technically suboptimal study, RV, RA, normal dimensions; } \\
\text { LA and LV normal dimensions, LV wall motion is normal; no } \\
\text { gross valvular abnormality; no thrombus, vegetation or effu- } \\
\text { sion; EF estimated @70 \% Cardiac Cath: not done }\end{array}$ & $\begin{array}{l}\text { Bipolar Disorder Suicide by methanol } \\
\text { poisoning; seizures }\end{array}$ \\
\hline NF19 & 61 & $M$ & White & Echo: Not done Cardiac Cath: not done & Intracranial hemorrhage \\
\hline NF20 & 58 & M & Black & $\begin{array}{l}\text { Echo: Global LV systolic function normal, RV systolic functions } \\
\text { normal, valves normal, no thrombus or effusion; EF } 65 \% \\
\text { Cariac Cath: not done }\end{array}$ & $\begin{array}{l}\text { Intracranial hemorrhage, hypertension, } \\
\text { DM }\end{array}$ \\
\hline
\end{tabular}

$D C M$ dilated cardiomyopathy, $N F$ non-failing heart (control), $E F$ ejection fraction, NIDDM non-insulin dependent diabetes mellitus, $M$ male, $F$ female

visually. Student's t test was used to test for a difference in mean abundance between normal and failing human hearts and between all of the human hearts and the rodent hearts. The significance of these comparisons was assessed using the false discovery rate (FDR) (Benjamini and Hochberg 2014). R version 2.15.1 (The R Project for Statistical Computing) was employed to make the comparisons and adjust the significance values ( $R$ Foundation for Statistical Computing 2014). Since some identified phosphoproteins were of a priori high interest, these were analyzed by $t$-test (Table 2 ).

\section{Results}

\section{Human hearts}

Tissues from failing $(\mathrm{n}=5)$ and control $(\mathrm{n}=5)$ human hearts (Table 1) were analyzed. Phosphoproteins from each heart were separated by 2D-DIGE (Fig. 1). The distribution of these favored the right upper and lower quadrants, corresponding to proteins with MW's 80 to $12 \mathrm{kDa} /$ PI's 6.8 to 9.0. Registered images were compiled. Mean (Fig. 2a) and standard deviation (Fig. 2b) plots showed the greatest abundance and variation in the proteins of the right upper quadrant. In identifying phosphoproteins with the greatest variability (variance in gray-unit scale) by 2D-DIGE, there is a bias toward ones with moderate abundance, in part due to censoring at extreme low or high levels. Ten phosphoproteins were chosen visually on the basis of both high abundance and standard deviation in composite images (Fig. 2a, b) for identification (Table 2) by MALDI-MS. A significant overall difference in standard differences in means of control and failing hearts (Fig. 3 and Additional file 1) could not be discerned. However, spot intensity was, in general, lowest in the lower right quadrant and greatest in lower left quadrant.

\section{Rodent hearts}

2D-DIGE images of phosphoproteins extracted from paired strains of failing and control rats strains, i.e., 1) Dahl salt-sensitive (S) and resistant (R) rat; and 2) Spontaneously hypertensive heart failure (SHHF) and Wistar rat strains (published previously (Kotlo et al. 2012)) were analyzed in composite using image registration (Fig. 4). The composite rectified images revealed a distribution of intensity of spots in all four quadrants, with the great concentration and variation in the right upper quadrant (Fig. 4).

\section{Comparison of cardiac phosphoproteins in humans versus rats}

The composite registered images from phosphoproteins extracted from human and rat hearts were compared (Figs. 5, 6). The range of differences in mean abundance for phosphoproteins from control versus failing human hearts was -15 to 12.67 , versus a range for human vs. rat differences of -116 to 227 . Mean and variance were different in human versus rodent hearts in $26 \%$ of the image planes. Mean abundance for the humans was lower than for the rodents in focal areas in each of the four quadrants and most profound in the left two-thirds of the images. The mean pixel intensity was higher for 


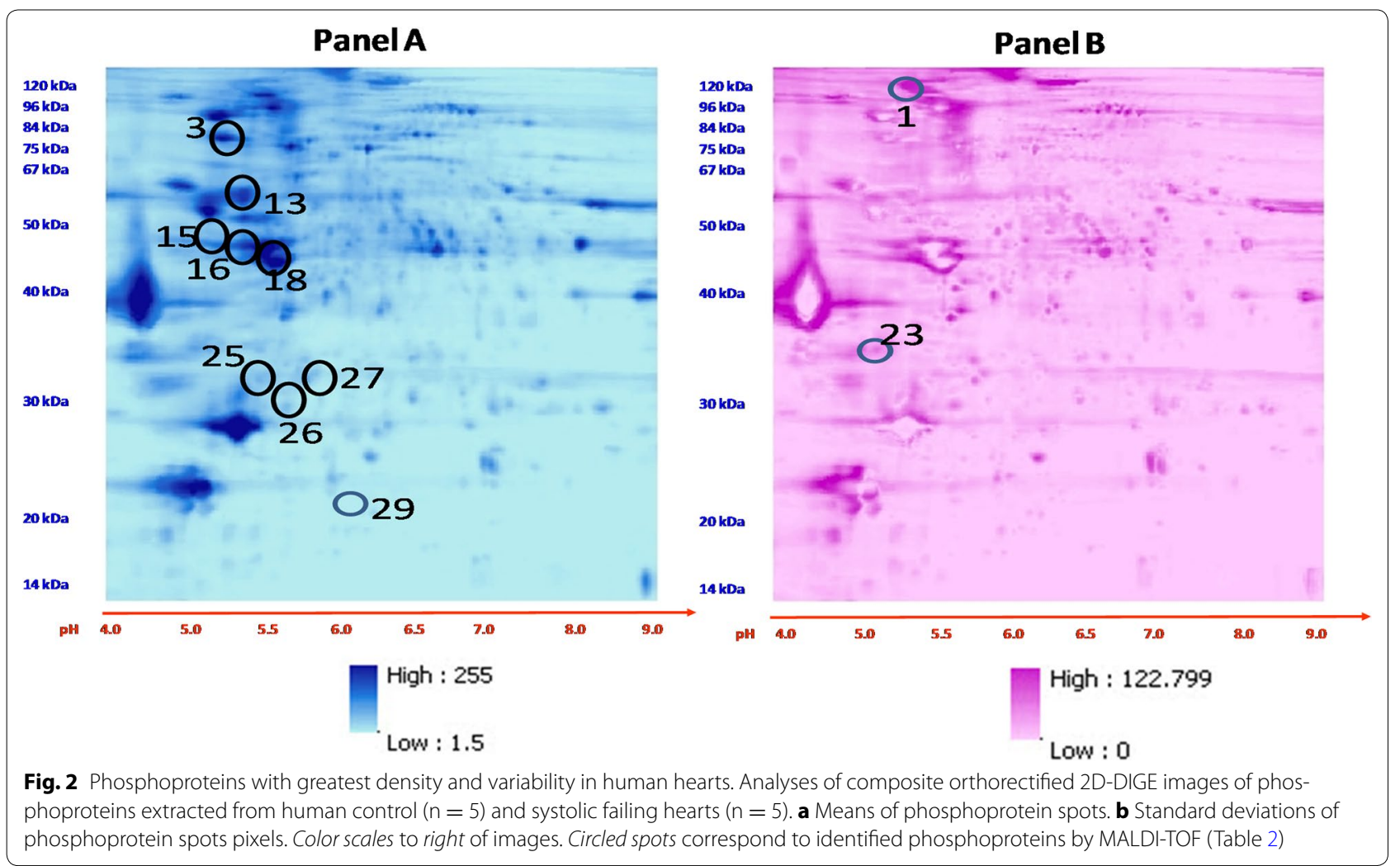

the rat hearts in a large proportion of the right third of the images. This analysis shows statistically significant $(\mathrm{p}<0.05)$ differences between cardiac phosphoproteins within combined groups of control and failing human versus rodent hearts.

The intensity spots for the identified phosphoproteins were compared between human and rodent hearts (Table 3). Specific phosphoproteins with significant differences between human versus rodent hearts were identified as $60 \mathrm{kDa}$ heat shock protein (spot \#13) troponin $\mathrm{T}$ (spot \#18), Myosin Light Chain 3 (spot \#25), peroxiredoxin (spot \#27), and haptoglobin (spot \#29).

\section{Discussion}

In the present study we have applied image registration to analyze phosphoproteins separated by 2D-DIGE from multiple human and rodent control and failing hearts in composite. The central findings are that there is great biological variability in the abundance of particular phosphoproteins in human and rodent hearts.

The mean plots constructed from 2D-DIGE images show great variation in phosphoproteins in human hearts, both within and between normal and failing heart samples. There are significant differences in the standard deviations and ranges of phosphoprotein abundances, indicating significant inter-individual variation.
In identifying phosphoproteins with the greatest variability (variance in gray-unit scale) by 2D-DIGE, there is a bias toward ones with moderate abundance, in part due to censoring at extreme low or high levels. Variation in the present study may not only arise from phosphorylations but also from variations in other post-translational modifications, (e.g., acetylation) which effect either MW or PI. However, the rectification and analysis process used should minimize this affecting phosphoprotein spot measurements.

We reason that the major source of variation in abundance of specific phosphoproteins observed is biological variability (versus replicative error). The overall statistical variation observed in the present study is consistent with that reported for proteomic analysis of human plasma (Corzett et al. 2010). 2D-DIGE gel to gel variability has previously been reported to be low with three or four replicates sufficient for compensation of variability, indicating that this does not introduce a significant bias with statistical confidence for individual spots (Burton and Hickey 2011). The etiology of biological variability is reasoned to arise from multiple sources, including genetic, environmental, and phenotypic cofounders. However, these may be very difficult to control for in that the variability of phosphoproteins in both rodents in the present and our previous data (Burton and Hickey 2011) 


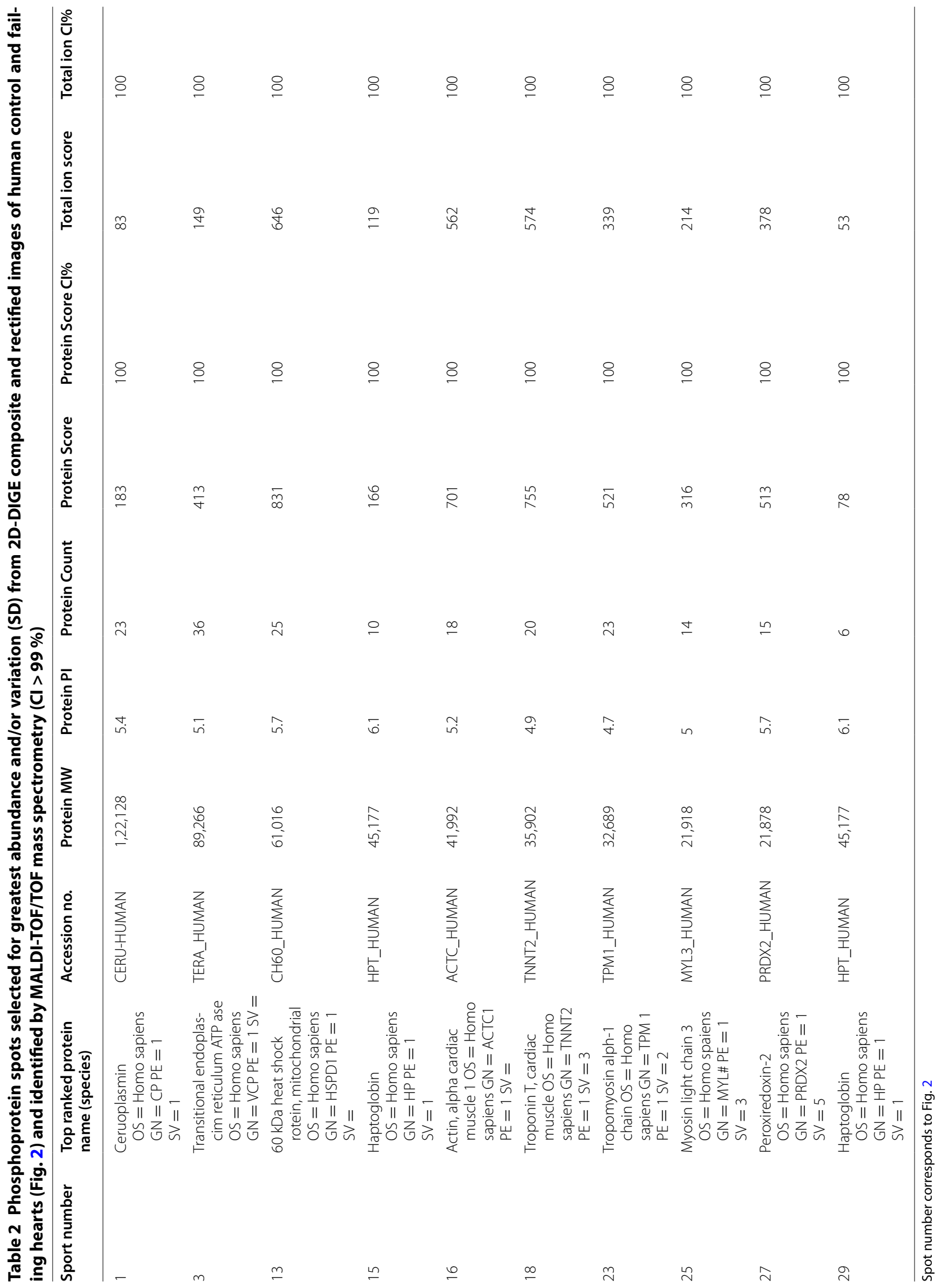




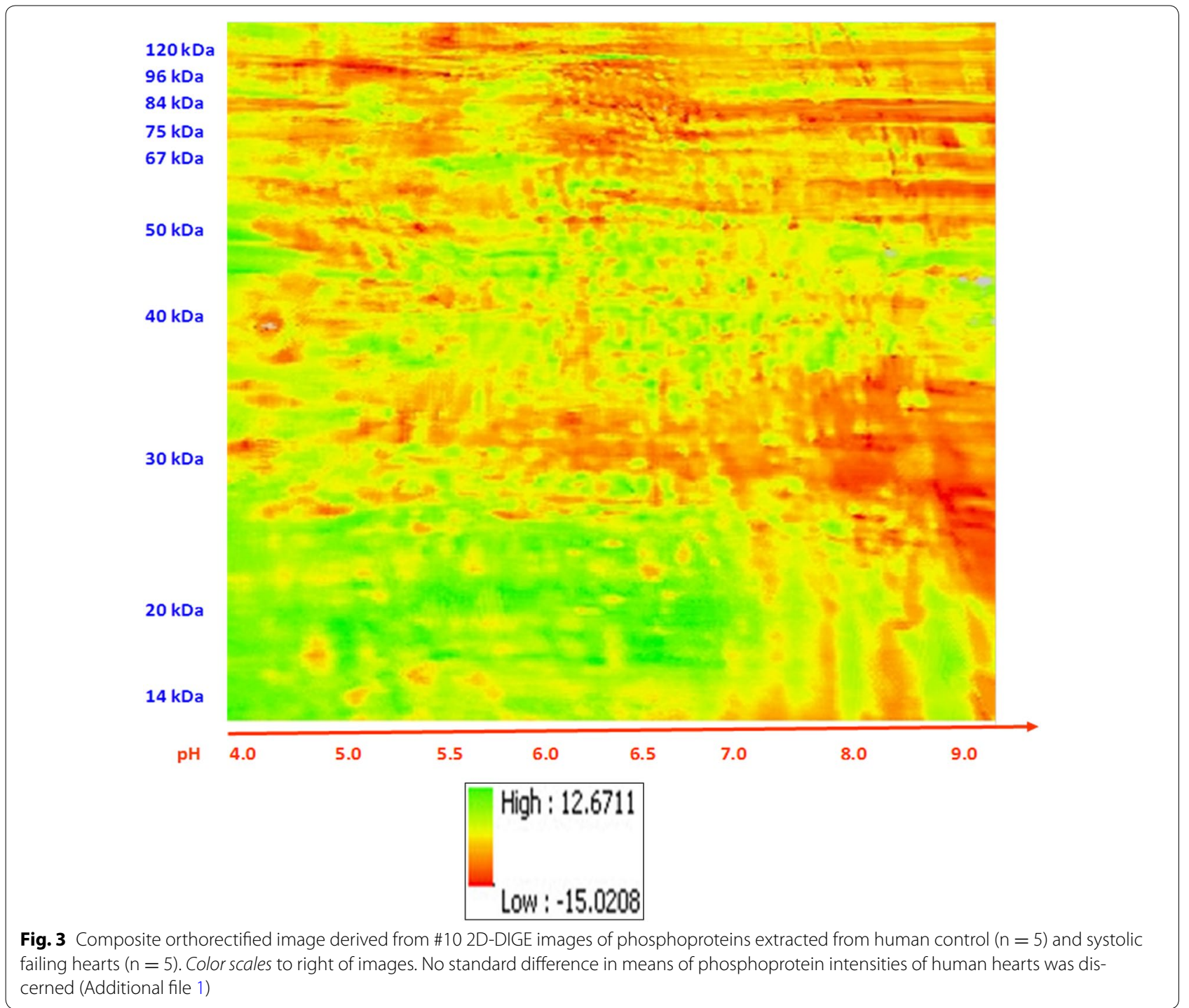

is marked, suggesting that even when there is greater genetic homogeneity and control over environment, inherent variability is observed. On the other hand, since phosphoproteins have different variability in abundance, some may require smaller sample sizes to discern difference, e.g., cMyBP-C (Kooij et al. 2013).

The variability of specific phosphoproteins in human hearts may be used to infer sample sizes required for clinical trials linking a protein modification to a phenotype, e.g., heart failure. We can use the biological variability reflected in phosphoproteins in the present study to determine requisite sample sizes frequently required to link a phosphorylation to a phenotype using inverse power analyses (Fig. 6). These power analysis shows that to detect small differences, studies with 1,000 to 10,000 subjects are required, in representative phosphoproteins identified in our study. The number of phosphoproteins with high variability suggests that improved phenotyping, which is usually based on a single or few indexes, in clinical trials is unlikely to reduce the prominence of inherent biological variability reflected in cell signaling and, required sample size for statistical power.

Rodent models have become a mainstay for the study of heart disease and failure, especially with hypertension. The present results show significant differences in the phosphoprotein patterns in rat versus human hearts in approximately one quarter of the area of compared rectified 2D-DIGE composite images. Among these phosphoproteins are ones known to be important in cardiac remodeling and function as well as ones not previously linked to the heart. Among the ones linked to cardiac functions/adaptation are phosphorylated heat shock protein 60 (HSP60) and troponin T. The likelihood of significant differences in phosphorylation of Troponin $\mathrm{T}$ is consistent with the lack of conservation 


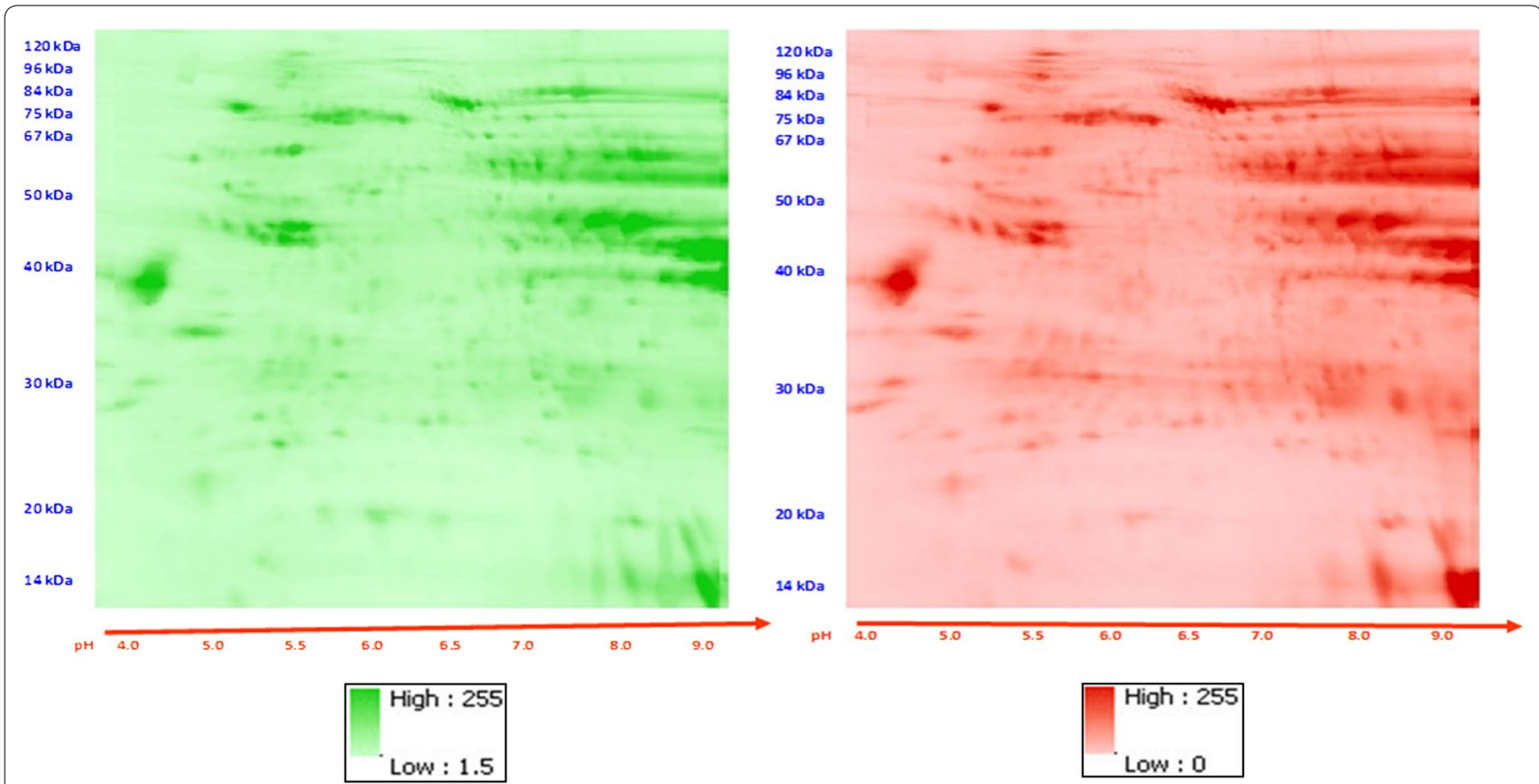

Fig. 4 A composite orthorectified image derived from \#4 2D-DIGE images of phosphoproteins extracted from control and failing rat hearts. a Means The colors represent the average difference between the controls and failing images and range from light blue (turquois) (small average differences) through dark blue (significant large average differences) (see color scales). b Standard deviations of means: The colors represent the average difference between the controls and failing images and range from light purple (small average differences) through dark purple (123) (see color scale) $(n=4)$. Greatest difference in phosphoprotein density and variability is noticed in the upper right quadrant

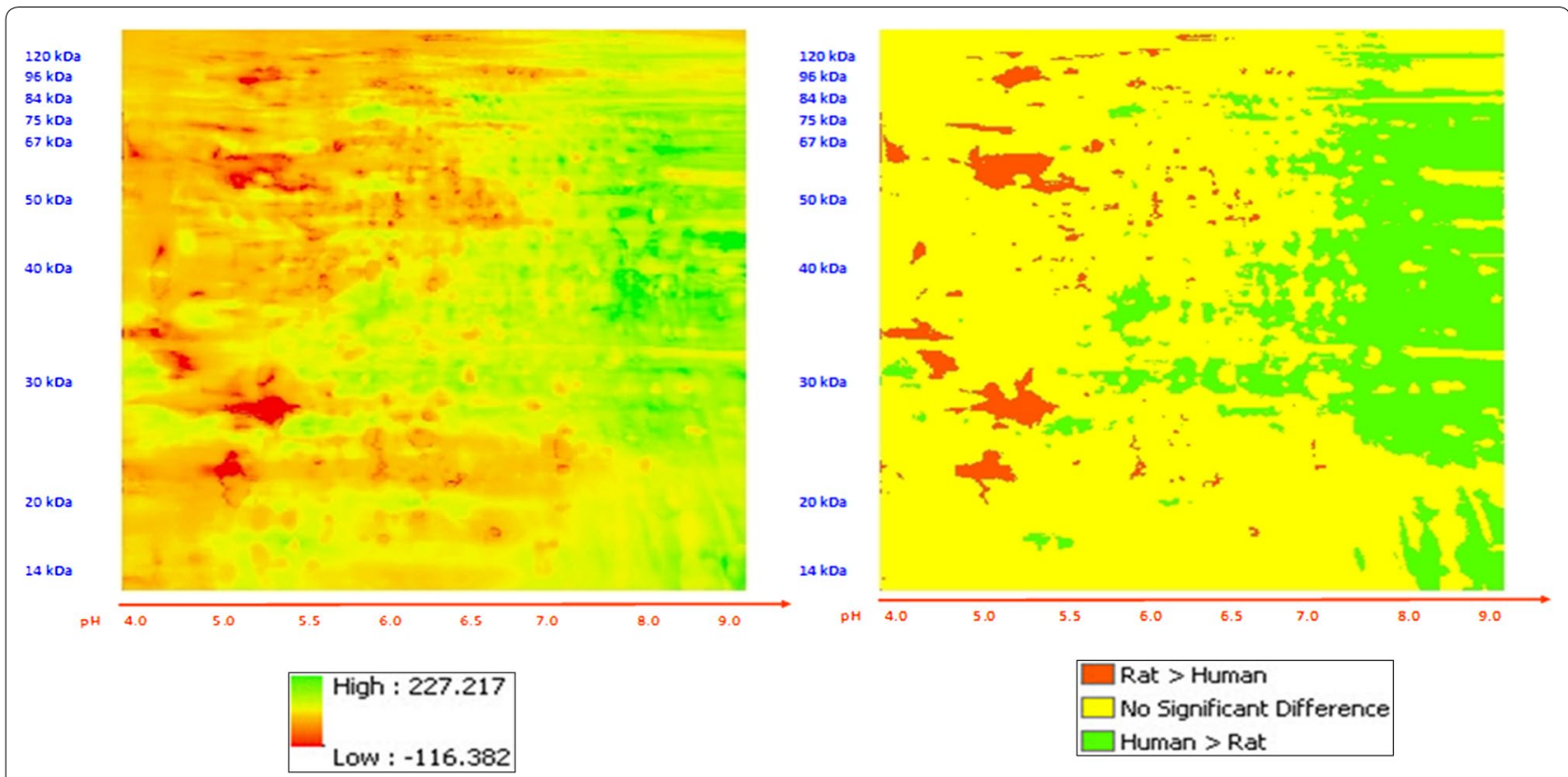

Fig. 5 Comparison of phosphoproteins in rodent versus human hearts. a Standardized differences. b Significance map. The bright pink areas indicate protein phosphorylations that are different between control and failing hearts. The light blue (turquois) areas indicate protein phosphorylations that are most uniform across all the heart samples. rat > human—red; human > rat—green 


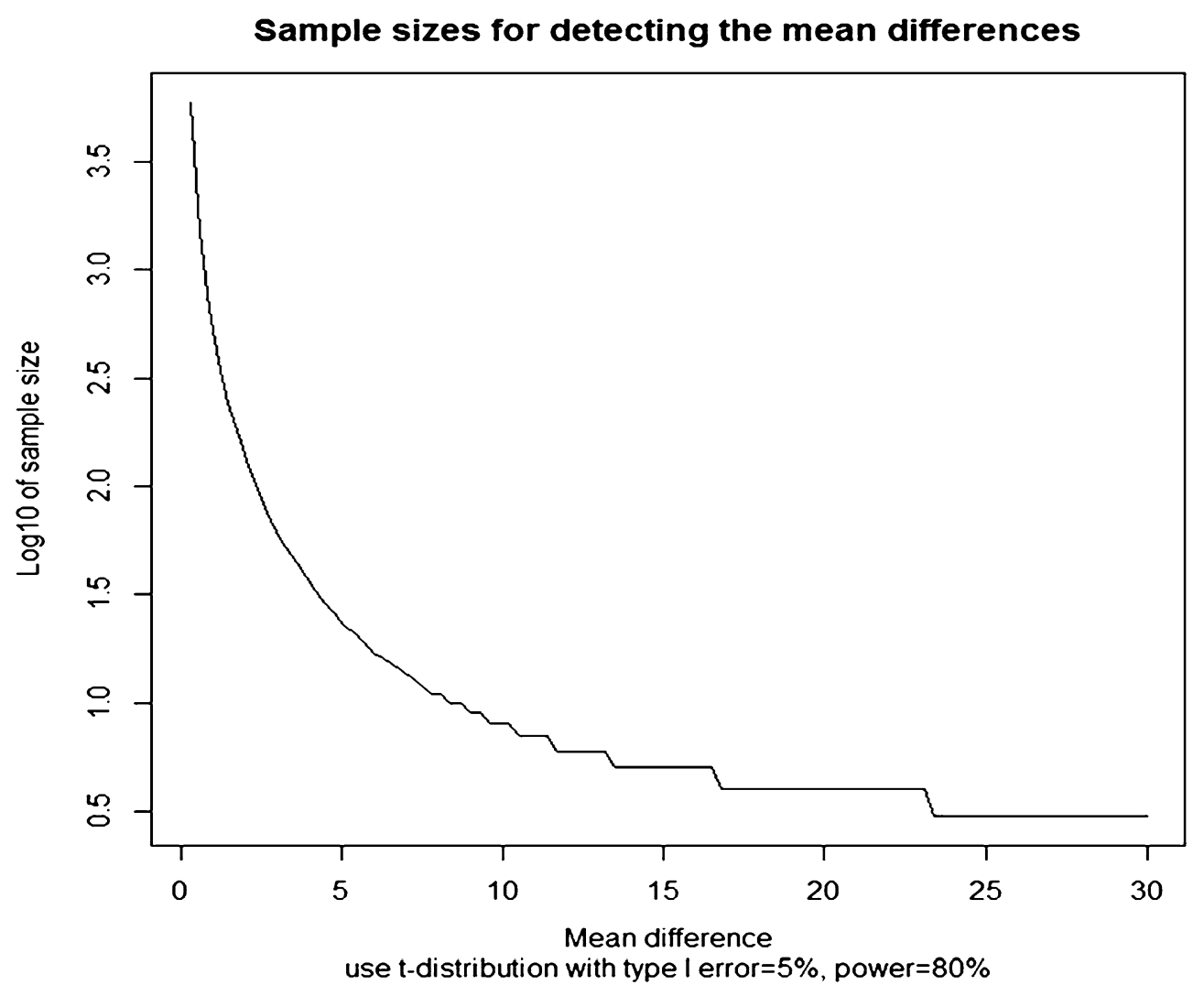

Fig. 6 Inverse power plot demonstrating sample size required to achieve $80 \%$ power with $5 \%$ type 1 error for the given group mean difference based on mean and standard deviation of phosphorylated peroxiredoxin (Table 3)

Table 3 Comparison of intensity (see Methods) of phosphoprotein spots selected from Fig. 2/Table 2 for increased abundance and/or variation (SD) in human versus rodent hearts

\begin{tabular}{|c|c|c|c|c|c|c|c|c|c|}
\hline Spot & Protein & Overall mean & Overall SD & Human mean & Human SD & Rat mean & Rat SD & $\mathbf{t}$ & $p$ value \\
\hline 1 & Cerulpolasmin & 63.42 & 36.12 & 52.62 & 25 & 90.42 & 49.19 & $(-) 1.46$ & 0.224 \\
\hline 3 & ER ATPs e & 78.88 & 46.56 & 67.45 & 47.78 & 107.47 & 31.94 & $(-) 1.82$ & 0.104 \\
\hline 13 & $60 \mathrm{kD}$ Heat Shock Protein & 84.1 & 32.7 & 93.82 & 32.83 & 59.78 & 17.21 & 2.52 & 0.0289 \\
\hline 15 & Haptagloblin & 85.05 & 27.84 & 85.85 & 28.69 & 83.06 & 29.69 & 0.16 & 0.8784 \\
\hline 16 & Actin, alpha cardiac muscle 1 & 120.84 & 48.81 & 122.79 & 36.78 & 115.99 & 78.87 & 0.17 & 0.8777 \\
\hline 18 & Troponin T cardiac muscle & 158.51 & 53.09 & 134.45 & 36.39 & 218.68 & 38.55 & $(-) 3.75$ & 0.0119 \\
\hline 23 & Tropomyosin alpha-1 chain & 202.96 & 44.58 & 192.67 & 46.69 & 228.7 & 28.9 & $(-) 1.74$ & 0.1144 \\
\hline 25 & Myos in light chain 3 & 99.82 & 94.05 & 43.03 & 14.26 & 241.81 & 9.55 & $(-) 30.27$ & $<0.0001$ \\
\hline 27 & Peroxiredoxin-2 & 26.18 & 14.6 & 31.63 & 13.86 & 12.56 & 1.29 & 4.3 & 0.0018 \\
\hline 29 & Haptagloblin & 22.23 & 28.72 & 29.04 & 31.74 & 5.21 & 3.36 & 2.34 & 0.0425 \\
\hline
\end{tabular}

Spot number-Fig. 2, protein-identification-Table 2; Overall mean/SD—mean and standard deviation of intensity of spots from composite rectified 2D-DIGE images of phosphoproteins from rodent and human hearts (Fig. 3). $t$ - $t$ value for human versus rodent

of phosphorylation motifs, e.g., troponin I Thr77 (review (Grzeskowiak et al. 2003)) in rodents versus humans. These findings may have major implications in the translation of rodent studies of the role of the phosphorylations of these proteins to humans and highlight the difficulties of such work (Hackam and Redelmeier 2006).

\section{Conclusions}

There are significant differences in the phosphorylation of key cardiac proteins in rodents and humans, makes confirmation of cardiac signaling involving phosphorylations, e.g., kinases, phosphodiesterases, phosphatases, in rodents in humans critical for translational work. The 
variability of specific phosphoproteins observed indicates large sample sizes, i.e., $1000-10,000$, are required to link a phenotype to a phosphoprotein.

\section{Additional file}

Additional file 1. Cardiac phosphoproteins.

\section{Abbreviations}

2D-DIGE: two-dimensional (2-D) difference gel electrophoresis (DIGE); Dahl S: Dahl salt-sensitive rat strain; Dahl R: Dahl salt-resistant rat strain; MALDI-MS: matrix-assisted laser desorption/ionization mass spectrometry; SHHF: spontaneously hypertensive heart failure prone rat strain.

\section{Authors' contributions}

KK performed phosphoprotein extractions from heart samples; SAM provided human heart samples and intellectual input; HYC performed statistics; JA performed rectification and analysis of images; RSD analyzed and coordinated the studies and wrote the manuscript. All authors read and approved the final manuscript.

\section{Author details}

${ }^{1}$ Division of Cardiology, University of Illinois at Chicago, 840 S. Wood St, Chicago, IL 60612, USA. ${ }^{2}$ The Cardiovascular Institute and the Department of Medicine, Loyola University Chicago Stritch School of Medicine, Building 110, Rm 5222, 2160 South First Avenue, Maywood, IL 60153, USA. ${ }^{3}$ Division of Epidemiology and Biostatistics, University of Illinois at Chicago, Chicago, IL 60612, USA. ${ }^{4}$ Department of Geography, University of Buffalo, 105 Wilkeson Quad, Buffalo, NY 14261, USA. ${ }^{5}$ Jesse Brown Veterans Administration, 820 S. Damen, Chicago, IL 60612, USA.

\section{Acknowledgements}

The discussions and suggestions of Todd Corvett (Lawrence Livermore Laboratory, CA) are appreciated.

\section{Competing interests}

The authors declare that they have no competing interests.

\section{Ethical approval of animals}

All animal studies were done in accordance with the Institutional Animal Care and Use Committee (IACUC).

\section{Ethical approval of human subjects}

All procedures performed in studies involving human participants were in accordance with the ethical standards of the institutional and/or national research committee and with the 1964 Helsinki declaration and its later amendments or comparable ethical standards.

\section{Funding}

This work was supported by NIH R21HL096031 (RSD) and Veterans Administration Merit Award (RSD).

Received: 30 November 2015 Accepted: 29 May 2016 Published online: 21 June 2016

\section{References}

Agnetti G, Kane LA, Guarnieri C, Caldarera CM, Van Eyk JE (2007) Proteomic technologies in the study of kinases: novel tools for the investigation of PKC in the heart. Pharmacol Res 55(6):511-522

Ai X, Pogwizd SM (2005) Connexin 43 downregulation and dephosphorylation in nonischemic heart failure is associated with enhanced colocalized protein phosphatase type 2A. Circ Res 96(1):54-63

Akar FG, Spragg DD, Tunin RS, Kass DA, Tomaselli GF (2004) Mechanisms underlying conduction slowing and arrhythmogenesis in nonischemic dilated cardiomyopathy. Circ Res 95(7):717-725
Altschuld RA, Starling RC, Hamlin RL, Billman GE, Hensley J, Castillo L et al (1995) Response of failing canine and human heart cells to beta 2-adrenergic stimulation. Circulation 92(6):1612-1618

Belin RJ, Sumandea MP, Allen EJ, Schoenfelt K, Wang H, Solaro RJ, de Tombe PP (2007) Augmented protein kinase C-alpha-induced myofilament protein phosphorylation contributes to myofilament dysfunction in experimental congestive heart failure. Circ Res 101(2):195-204

Benjamini Y, Hochberg (2014) Controlling the false discovery rate: a practical and powerful approach to multiple testing. J Roy Stat Soc 57:289

Benkusky NA, Weber CS, Scherman JA, Farrell EF, Hacker TA, John MC et al (2007) Intact beta-adrenergic response and unmodified progression toward heart failure in mice with genetic ablation of a major protein kinase A phosphorylation site in the cardiac ryanodine receptor. Circ Res 101(8):819-829

Blankesteijn WM, van de Schans V, Ter Horst P, Smits JF (2008) The Wnt/frizzled/ GSK-3beta pathway: a novel therapeutic target for cardiac hypertrophy. Trends Pharmacol Sci 29(4):175-180

Brown LG (1992) A survey of image registration techniques. ACM computing surveys (CSUR) 24:325-376

Burton EO, Hickey WJ (2011) Assessing variability in gel-based proteomic analysis of Nitrosomonas europaea. Methods Enzymol 496:435-463

Cantley LC (2002) The phosphoinositide 3-kinase pathway. Science 296(5573):1655-1657

Corzett TH, Fodor IK, Choi MW, Walsworth VL, Turteltaub KW et al (2010) A statistical analysis of variation in the human plasma proteome. J. Biomed. Biotechnol. 2010:258494

Desantiago J, Ai X, Islam M, Acuna G, Ziolo MT, Bers DM, Pogwizd SM (2008) Arrhythmogenic effects of \{beta\}2-adrenergic stimulation in the failing heart are attributable to enhanced sarcoplasmic reticulum Ca load. Circ Res 102:1389-1397

Dousa TP (1999) Cyclic-3',5'-nucleotide phosphodiesterase isozymes in cell biology and pathophysiology of the kidney. Kidney Int 55(1):29-62

Fielitz J, Kim MS, Shelton JM, Qi X, Hill JA, Richardson JA et al (2005) Requirement of protein kinase D1 for pathological cardiac remodeling. Proc Natl Acad Sci USA 105(8):3059-3063

Frantz S, Behr T, Hu K, Fraccarollo D, Strotmann J, Goldberg E et al (2007) Role of p38 mitogen-activated protein kinase in cardiac remodelling. $\mathrm{Br} \mathrm{J}$ Pharmacol 150(2):130-135

Fukuda N, Wu Y, Nair P, Granzier HL (2005) Phosphorylation of titin modulates passive stiffness of cardiac muscle in a titin isoform-dependent manner. J Gen Physiol 125(3):257-271

Gill RM, Braz JC, Jin N, Etgen GJ, Shen W (2005) Restoration of impaired endothelium-dependent coronary vasodilation in failing heart: role of eNOS phosphorylation and CGMP/cGK-I signaling. Am J Physiol Heart Circ Physiol 292(6):H2782-H2790

Grote-Wessels S, Baba HA, Boknik P, El-Armouche A, Fabritz L, Gillmann HJ et al (2008) Inhibition of protein phosphatase 1 by inhibitor-2 exacerbates progression of cardiac failure in a model with pressure overload. Cardiovasc Res 79:464-471

Grzeskowiak R, Witt H, Drungowski M, Thermann R, Hennig S, Perrot A et al (2003) Expression profiling of human idiopathic dilated cardiomyopathy. Cardiovasc Res 59(2):400-411

Gupta RC, Mishra S, Rastogi S, Imai M, Habib O, Sabbah HN (2003) Cardiac SRcoupled PP1 activity and expression are increased and inhibitor 1 protein expression is decreased in failing hearts. Am J Physiol Heart Circ Physiol 285(6):H2373-H2381

Gupta RC, Mishra S, Yang XP, Sabbah HN (2005) Reduced inhibitor 1 and 2 activity is associated with increased protein phosphatase type 1 activity in left ventricular myocardium of one-kidney, one-clip hypertensive rats. Mol Cell Biochem 269(1-2):49-57

Hackam DG, Redelmeier DA (2006) Translation of research eveidence from animals to humans. JAMA 296:1727-1732

Harrison BC, Kim MS, van Rooij E, Plato CF, Papst PJ, Vega RB et al (2006) Regulation of cardiac stress signaling by protein kinase d1. Mol Cell Biol 26(10):3875-3888

Heineke J, Ruetten H, Willenbockel C, Gross SC, Naguib M, Schaefer A et al (2005) Attenuation of cardiac remodeling after myocardial infarction by muscle LIM protein-calcineurin signaling at the sarcomeric Z-disc. Proc Natl Acad Sci USA 102(5):1655-1660 
Kooij V, Holewinski RJ, Murphy AM, Van Eyk JE (2013) Characterization of the cardiac myosin binding protein-C phosphoproteome in healthy and failing human hearts. J Mol Cell Cardiol 60:116-120

Kotlo K, Johnson K, Grillon JM, Geenen DL, deTombe P, Danziger RS (2012) Phosphoprotein abundance changes in hypertensive cardiac remodeling. Joural of Proteomics. 77:1-13

Lai NC, Tang T, Gao MH, Saito M, Takahashi T, Roth DM, Hammond HK (2008) Activation of cardiac adenylyl cyclase expression increases function of the failing ischemic heart in mice. J Am Coll Cardiol 51(15):1490-1497

Lehnart SE, Wehrens XH, Reiken S, Warrier S, Belevych AE, Harvey RD et al (2005) Phosphodiesterase 4D deficiency in the ryanodine-receptor complex promotes heart failure and arrhythmias. Cell 123(1):25-35

Liu X, Sun SQ, Hassid A, Ostrom RS (2006) CAMP inhibits transforming growth factor-beta-stimulated collagen synthesis via inhibition of extracellular signal-regulated kinase $1 / 2$ and Smad signaling in cardiac fibroblasts. Mol Pharmacol 70(6):1992-2003

Matsui T, Li L, Wu JC, Cook SA, Nagoshi T, Picard MH et al (2002) Phenotypic spectrum caused by transgenic overexpression of activated Akt in the heart. J Biol Chem 277(25):22896-22901

Matus M, Lewin G, Stumpel F, Buchwalow IB, Schneider MD, Schutz G et al (2007) Cardiomyocyte-specific inactivation of transcription factor CREB in mice. FASEB J. 21(8):1884-1892

Milting H, Scholz C, Arusoglu L, Freitag M, Cebulla R, Jaquet K et al (2006) Selective upregulation of beta1-adrenergic receptors and dephosphorylation of troponin I in end-stage heart failure patients supported by ventricular assist devices. J Mol Cell Cardiol 41(3):441-450

Movsesian MA, Colyer J, Wang JH, Krall J (1990) Phospholamban-mediated stimulation of $\mathrm{Ca} 2+$ uptake in sarcoplasmic reticulum from normal and failing hearts. J. Clin. Invest. 85(5):1698-1702

Muller FU, Boknik P, Horst A, Knapp J, Linck B, Schmitz W et al (1995) CAMP response element binding protein is expressed and phosphorylated in the human heart. Circulation 92(8):2041-2043

Muller FU, Boknik P, Knapp J, Neumann J, Vahlensieck U, Oetjen E et al (1998) Identification and expression of a novel isoform of cAMP response element modulator in the human heart. FASEB J. 12(12):1191-1199

Muller FU, Boknik P, Knapp J, Linck B, Luss H, Neumann J, Schmitz W (2001) Activation and inactivation of CAMP-response element-mediated gene transcription in cardiac myocytes. Cardiovasc Res 52(1):95-102

Napolitano R, Vittone L, Mundina C, de Cingolani GC, Mattiazzi A (1992) Phosphorylation of phospholamban in the intact heart A study on the physiological role of the $\mathrm{Ca}(2+)$-calmodulin-dependent protein kinase system. J Mol Cell Cardiol 24(4):387-396

van der Velden J, Papp, Z., Boontje, N. M., Zaremba, R., de Jong, J. W., Janssen, P. M. et al. (2003). Myosin light chain composition in non-failing donor and end-stage failing human ventricular myocardium. Adv.Exp.Med.Biol. 538:3-15:3-15

Pathak A, del Monte F, Zhao W, Schultz JE, Lorenz JN, Bodi I et al (2005) Enhancement of cardiac function and suppression of heart failure progression by inhibition of protein phosphatase 1. Circ Res 96(7):756-766

R Foundation for Statistical Computing (2014) PrFont34BinOBinSubOFracODef1Margin0Margin0Jc1 Indent1440LimOLim1R: A language and environment for statistical computing. 2.15.1, R Foundation for Statistical Computing, Vienna, Austria

Sakata Y, Masuyama T, Yamamoto K, Nishikawa N, Yamamoto H, Kondo H et al (2000) Calcineurin inhibitor attenuates left ventricular hypertrophy, leading to prevention of heart failure in hypertensive rats. Circulation 102(18):2269-2275

Schiekofer S, Shiojima I, Sato K, Galasso G, Oshima Y, Walsh K (2006) Microarray analysis of Akt1 activation in transgenic mouse hearts reveals transcript expression profiles associated with compensatory hypertrophy and failure. Physiol Genomics 27(2):156-170

Schwinger RH, Bolck B, Munch G, Brixius K, Muller-Ehmsen J, Erdmann E (1998) CAMP-dependent protein kinase A-stimulated sarcoplasmic reticulum function in heart failure. Ann. N.Y. Acad. Sci. 853:240-250

Shioi T, Kang PM, Douglas PS, Hampe J, Yballe CM, Lawitts J, Cantley LC, Izumo $S$ (2000) The conserved phosphoinositide 3-kinase pathway determines heart size in mice. EMBO J 19(11):2537-2548

Shiojima I, Walsh K (2006) Regulation of cardiac growth and coronary angiogenesis by the Akt/PKB signaling pathway. Genes Dev 20(24):3347-3365
Skurk C, Izumiya Y, Maatz H, Razeghi P, Shiojima I, Sandri M et al (2005) The FOXO3a transcription factor regulates cardiac myocyte size downstream of AKT signaling. J Biol Chem 280(21):20814-20823

Sumandea MP, Pyle WG, Kobayashi T, de Tombe PP, Solaro RJ (2003) Identification of a functionally critical protein kinase $\mathrm{C}$ phosphorylation residue of cardiac troponin T. J Biol Chem 278(37):35135-35144

Sumandea MP, Burkart EM, Kobayashi T, de Tombe PP, Solaro RJ (2004) Molecular and integrated biology of thin filament protein phosphorylation in heart muscle. Ann NY Acad Sci 1015:39-52

Takahashi T, Tang T, Lai NC, Roth DM, Rebolledo B, Saito M et al (2006) Increased cardiac adenylyl cyclase expression is associated with increased survival after myocardial infarction. Circulation 114(5):388-396

Takeishi Y, Huang Q, Abe J, Che W, Lee JD, Kawakatsu H et al (2002) Activation of mitogen-activated protein kinases and p90 ribosomal $\$ 6$ kinase in failing human hearts with dilated cardiomyopathy. Cardiovasc Res 53(1):131-137

Vahtola E, Louhelainen M, Merasto S, Martonen E, Penttinen S, Aahos I et al (2008) Forkhead class O transcription factor 3a activation and Sirtuin1 overexpression in the hypertrophied myocardium of the diabetic GotoKakizaki rat. J Hypertens 26(2):334-344

Van Oort RJ, van Rooij E, Bourajjaj M, Schimmel J, Jansen MA, van der Nagel $R$ et al (2006) MEF2 activates a genetic program promoting chamber dilation and contractile dysfunction in calcineurin-induced heart failure. Circulation 114(4):298-308

Vega RB, Harrison BC, Meadows E, Roberts CR, Papst PJ, Olson EN, McKinsey $T$ (2004) A. Protein kinases C and D mediate agonist-dependent cardiac hypertrophy through nuclear export of histone deacetylase 5. Mol Cell Biol 24(19):8374-8385

Vittone L, Mundina-Weilenmann C, Mattiazzi A (2008) Phospholamban phosphorylation by CaMKII under pathophysiological conditions. Front Biosci. 13:5988-6005

Wohlschlaeger J, Schmitz KJ, Palatty J, Takeda A, Takeda N, Vahlhaus C et al (2007) Roles of cyclooxygenase-2 and phosphorylated Akt (Thr308) in cardiac hypertrophy regression mediated by left-ventricular unloading. J Thorac Cardiovasc Surg 133(1):37-43

Wrana JL, Attisano L, Wieser R, Ventura F, Massague J (1994) Mechanism of activation of the TGF-beta receptor. Nature 370(6488):341-347

Zhang T, Johnson EN, Gu Y, Morissette MR, Sah VP, Gigena MS et al (2002a) The cardiac-specific nuclear delta(B) isoform of Ca2+/calmodulin-dependent protein kinase II induces hypertrophy and dilated cardiomyopathy associated with increased protein phosphatase 2A activity. J Biol Chem 277(2):1261-1267

Zhang CL, McKinsey TA, Chang S, Antos CL, Hill JA, Olson EN (2002b) Class II histone deacetylases act as signal-responsive repressors of cardiac hypertrophy. Cell 110(4):479-488

Zhang R, Khoo MS, Wu Y, Yang Y, Grueter CE, Ni G et al (2005) Calmodulin kinase II inhibition protects against structural heart disease. Nat Med 11(4):409-417

Zhu WZ, Wang SQ, Chakir K, Yang D, Zhang T, Brown JH et al (2003) Linkage of beta1-adrenergic stimulation to apoptotic heart cell death through protein kinase A-independent activation of $\mathrm{Ca} 2+/$ calmodulin kinase II. J. Clin. Invest. 111(5):617-625

\section{Submit your manuscript to a SpringerOpen ${ }^{\circ}$ journal and benefit from:}

- Convenient online submission

- Rigorous peer review

- Immediate publication on acceptance

- Open access: articles freely available online

- High visibility within the field

- Retaining the copyright to your article

Submit your next manuscript at springeropen.com 